\title{
THE STUDY OF ADHESIVE PROPERTIES OF POLYMERIC SHOE ADHESIVE COMPOSITIONS
}

\author{
M. Shalamberidze1, M. Tatvidze ${ }^{2}$
}

DOI: http://doi.org/10.15350/L_26/11/6

\section{Abstract}

The article considers the interfacial adhesion phenomena in the interaction of dissimilar bodies. it is Proved that the crucial factor for adhesion is the polarity of chemical bonds, which determine the reactivity of adhesives. Studies have shown that high adhesive strength is achieved in the interaction of donor acceptor groups of the adhesive and the substrate.

Keywords: Adhesive composition, adhesive properties.

Полимерные композиционные материалы - это гетерофазные системы, полученные из двух или более компонентов. Полимерные композиционные материалы в обувной промышленности применяются в виде клеевых композиций и композиционных материалов для деталей низа обуви. Применение новых искусственных и синтетических материалов различного химического состава для верха и низа обуви, клеевого метода крепления, вызвало необходимость разработки новых модифицированных обувных клеев-растворов (полиуретановых, полихлоропреновых и др.). Основным показателем качества клеевых соединений является их прочность, определяемая в первую очередь адгезионными и когезионными свойствами клеев и склеиваемых материалов $[1-2,5]$.

Адгезионная связь возникает в результате действия межмолекулярных сил или сил химического взаимодействия молекул, приведенных в контакт разнородных поверхностей, при этом образуется связь на границе раздела фаз адгезив - субстрат. Адгезия как межфазное явление взаимодействия разнородных тел и имеет особое значение для получения гетерофазных систем. Адгезионное взаимодействие, как правило, появляется на уровне молекулярных агрегатов, мицелл, надмолекулярных образований и т. д. Его отличительной особенностью является возникновение взаимодействия между молекулами, входящими в поверхностные слои конденсированных фаз [6-8].

\footnotetext{
${ }^{1}$ Merab Shalamberidze, Doctor of Technical Sciences, Professor, Akaki Tsereteli State University, Georgia.

${ }^{2}$ Tatvidze Malvina, Doctor of Chemical and Biological Engineering, Associated Professor, Akaki Tsereteli State University, Georgia.

*The work was executed with the financial support of Shota Rustaveli National Science Foundation, Grant FR № 217386
} 
Рассматривая условия образования адгезионных соединений, необходимо различать макро - и микропроцессы. Первые из них направлены на формирование молекулярного контакта - сближения поверхностей конденсированных фаз на расстояния достаточные для возникновения межфазных связей в результате развития микропроцесса межфазного взаимодействия.

Молекулярно - кинетический подход к процессу адгезии позволяет учесть особенности влияния реальной природы контактирующих полимеров расположенной межфазной зоны на основные закономерности образования и поведения адгезионных соединений. Начальным актом межфазного взаимодействия адгезива и субстрата является адсорбция. При адсорбции межфазный контакт определяется конформационным набором макромолекул, которые могут иметь форму гауссова клубка, петли или плоской ленты. Анализ литературных данных [2, 4, 6-7] показывает, что адсорбция полимеров на границе фаз не сопровождается скачком энергии взаимодействия и представляет собой фазовый переход II рода, тогда как переход макромолекулы из свободного объема (раствора) в ограниченное пространство (субстрата) имеет дискретную энергетическую природу, т. е. это - фазовый переход I рода с энтальпийным эффектом [6]. Вместе с тем анализ адгезионного взаимодействия по аналогии с адсорбцией в ряде случаев позволяет установить некоторые общие закономерности межфазовых процессов и выявить факторы, ответственные за их проявление. Из этих соображений следует, что свободная энергия F макромолекулярных цепей, закрепленных единичными точками на поверхности субстрата вследствие протекания химической реакции, определяется свободными энергиями изолированной цепи $\mathrm{F}_{1}$, единственного закрепленного локального участка $\mathrm{F}_{2}$ и участка между местами закрепления $\mathrm{F}_{3}$ :

$$
\mathrm{F}=\mathrm{nF}_{1}+\mathrm{zF}_{2}+\mathrm{F}_{3}-\mathrm{RT} \ln \mathrm{W}_{\mathrm{z}}(1)
$$

где $\mathrm{n}$ - степень полимеризации; z - число закреплений; последний член этого уравнения $\mathrm{W}_{\mathrm{z}}$ учитывает вероятность различных способов осуществления межфазного контакта [2, 4, 6-7].

Иной подход к рассмотрению закономерностей межфазного взаимодействия адгезив - субстрат основан на анализе результатов разрушения адгезионных соединений в рамках кинетической концепции прочности, т. е. исходя из анализа зависимости долговечности $\tau$ от напряжения $\gamma$, имеющей вид:

$$
\tau=\tau_{0} \exp \left(\mathrm{U}_{\mathrm{a}}-\lambda \gamma / \mathrm{KT}\right)(2)
$$

где $\mathrm{U}_{\mathrm{a}}$ - энергия активации. Для гетерогенных систем следует учитывать также внутренние напряжения $\gamma$, величина которых зависит от технологии формирования соединения:

$$
\tau=\tau_{0} \exp \left\{\left[\mathrm{U}_{\mathrm{a}}-\lambda\left(\gamma \pm \gamma_{0}\right)\right] / \mathrm{KT}\right\}(3)
$$

Экспотенциальной зависимостью определяется также кинетика изменения $\gamma_{0}$, согласно:

$$
\mathrm{d} \gamma_{0}=\mathrm{E}_{\mathrm{a}} \mathrm{d} \xi_{\mathrm{a}}(4)
$$




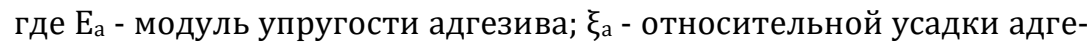
зива в процессе структурирования после завершения гелеообразования. Поскольку существует связь между $E_{a}$ и $\xi_{\mathrm{a}}$ и кинетическими параметрами роста прочности адгезионных соединении [2-3], величина внутренних напряжений должна определяться кажущейся энергией активации процесса структурирования Üं начала процесса структурирования и время перехода адгезива в гелеобразное состояние)

$$
\gamma_{0}=0,5 \mathrm{E} \infty \xi_{\infty}\left[1-\exp -\left(\tau_{\tau}-\tau_{\mathrm{g}} / \tau_{\mathrm{g}} \exp \left(\mathrm{U}_{\mathrm{a}} / \mathrm{RT}\right)\right)\right]^{2}(5)
$$

(индекс $\infty$ обозначает равновесное состояние). Справедливость последнего экспоненциального уравнения подтверждена на примере полимерных адгезивов [2-3, 6-7].

Все разновидности межмолекулярных взаимодействий (ориентационные, индукционные, дисперсионное) могут участвовать в образовании адгезионной связи между адгезивом и субстратом, а преобладающее значение того или иного типа сил зависит от конкретных склеиваемых объектов. Ориентационные и индукционные силы возникают при взаимодействии полярных молекул. Дисперсионные силы обусловлены взаимодействием мгновенных дипольных моментов, возникающих в результате флуктуаций электронной плотности контактирующих молекул. Энергия межмолекулярного взаимодействия имеет следующие значения, кДж/моль: ориентационной до 20, индукционной до 2 и дисперсионной до 40. При наличии в молекулах адгезива и субстрата электроотрицательных атомов фтора, кислорода, азота вблизи атомов водорода, связанных в свою очередь также при адгезионном взаимодействии, возможно образование

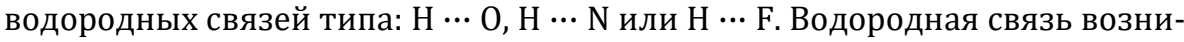
кает, когда водородный атом находится между донором и акцептором протонов. Энергия водородных связей больше, чем энергия Ван-дер-ваальсового взаимодействия и обычно имеет величину до 50 кДж/моль, а в некоторых случаях достигает 120 кДж/моль. Водородные связи являются причиной сильной когезии ряда материалов, обычно содержащих большое число гидроксильных и аминных групп. При наличии потенциальных возможностей образования водородных связей между адгезивом и субстратов можно ожидать значительного увеличения адгезии.

В определенных случаях адгезионная связь обуславливается химическими реакциями в зоне контакта, в результате которых образуются химические связи - ковалентные, ионные и координационные. Энергия химических связей значительно выше, чем энергия межмолекулярных водородных связей и составляет от 100 до 1000 кДж/моль. Одним из распространенных видов межмолекулярных связей являются донорно - акцепторные.

По признаку убывания электронно - донорных свойств функциональные группы молекул можно расположить в ряд, в котором каждый предыдущий член является донором по отношению к последующему: донор $\mathrm{NH}_{2}>\mathrm{OH}>\mathrm{OR}>\mathrm{OCOR}>\mathrm{CH}_{3}>\mathrm{C}_{6} \mathrm{H}_{5}>$ галоиды $>\mathrm{COOR}>\mathrm{CO}>\mathrm{CN}$ акцептор. Адгезия повышается по мере удаления друг от друга функциональных 
групп соединяемых полимеров в донорно - акцепторному ряду. Комбинируя места в донорно - акцепторном ряду функциональных групп молекул адгезива и склеиваемых материалов, можно достичь высоких значений адгезионной прочности.

При разработке оптимальных составов обувных клеев необходимо учитывать донорно - акцепторные свойства функциональных групп адгезива и субстрата. Например, условиям донорно - акцепторного ряда отвечает применение полиуретанового клея для склеивания искуственных кож с поливинилхлоридным покрытием. В этом случае функциональные группы адгезива и субстрата отстоят в донорно - акцепторном ряду друг от друга достаточно далеко, поскольку адгезив имеет гидроксильные -OH и уретановые -NHOCO- группы, а субстрат содержит радикалы хлора и винильные группировки. Более низкие показатели адгезии полиуретановых клеев к резинам на основе бутадиен - стирольного каучука. Это можно объяснить близкими электронно - донорными свойствами молекул адгезива и каучука, составляющего основу резины.

Полихлоропреновый клей обладает значительно большей адгезией к резинам на основе бутадиен - нитрильного каучука, чем к резинам на основе бутадиен - стирольного каучука, так как группы, образующие адгезионные пары, более различаются по донорно - акцепторным свойствам, чем пары из групп - CI и - ${ }_{6} \mathrm{H}_{5}$ бутадиен - стирольного каучука.

Принципиально важным для адгезии является также полярность химических связей, которые определяют реакционную способность адгезивов. Полярными обычно являются полимеры, содержащие в макромолекуле следующие группы: C-OH, C- NH2, C-COOH, C-CI, C-OCOR и др. Полярность играет двойную роль при склеивании. Она влияет как на когезионные, так на адгезионные характеристики клеевых композиций [1, 2-4, 6-8].

Если между адгезивом и субстратом возможно образование химических связей и адгезив при формировании клеевого соединения способен к структурированию (вулканизации, отверждению), образуются клеевые соединения, характеризующиеся повышенной прочностью, теплостойкостью и стойкостью к агрессивным средам.

Таким образом, при разработке новых полимерных клеевых композиций и проектировании технологического процесса склеивания, нужно стремиться к возможно более высокой прочности и надежности клеевых соединений, соответствующей назначению клеевого шва и требованиям, предъявляемым к нему при оптимальной конечной прочности адгезива.

\section{References:}

[1] Берлин А.А., Вольфсон С.А., Осимян В.Г., Ениколопов Н.С. Принципы создания композиционных полимерных материалов. М.: Химия, 1990, 240 с.

[2] Аскадский А.А., Матвеев Ю.И. Химическое строение и физические свойства полимеров. М.: Химия, 1983, с. 348.

[3] Нарисава И. Прочность полимерных материалов. М.: Химия, 1987, 397с.

[4] Денисов Е.Т., Саркисов О.М., Лихтенштейн Г.И. Химическая кинетика. М.: Химия, 2000,565 c. 
[5] Виноградова Л.А. Разработка и применение новых клеев для производства обуви. // Кожевенно-обувная промышленность. 1998, № 6, с.16-17.

[6] Вакула В.Л., Притикин Л.М. Физическая химия адгезии полимеров. М.: Химия, 1984, 221c.

[7] Марч Дж. Реакции, механизмы и структуры. Органическая химия.Т.1. М.: Мир, $1987,371 c$

[8] Липатов Ю.С. Межфазные явления в полимерах. Киев, Наукова думка: 1980, $260 \mathrm{c}$. 